\title{
Close, but not close enough? Audience's reactions to domesticated distant suffering in international news coverage
}

Eline Huiberts \& Stijn Joye, Ghent University

\begin{abstract}
$\underline{\text { Abstract }}$
Journalists domesticate news about distant events to bring such events closer to the audience and thus make them more relevant and appealing; however, knowledge about the actual audience's reactions towards domesticated news is lacking. Central to this study is understanding how an audience makes use of domestication strategies in viewing and reacting to mediated distant suffering. Earlier text-based research has found several ways of domesticating distant suffering that can invite an audience to care (Joye, 2015). Building further on this media-centered study, ten focus groups reveal a two-flow model of domestication, consisting of first-level domestication on the production side by journalists and second-level domestication, in which audience members themselves use strategies of domestication to make sense of distant suffering.
\end{abstract}

Keywords: distant suffering; domestication; audience research; social psychology; focus groups; news media

\section{$\underline{\text { Introduction }}$}

Meredith (23): 'I have difficulty empathizing. It's terrible of me I think, but personally, I've forgotten about it already the next day. Because, well, it's so far away, and it won't happen here anyway, so I don't really feel personally involved. I do think about, like, how they are going to live in the future, with all that poverty and misery. But then I think more about the 
consequences for them, and well, that disappears, because you're not personally involved or included in any kind of help organization or something. ${ }^{11}$ (focus group 3, female group, high education level)

The above quote of Meredith, a young Belgian woman who took part in one of the focus groups, was in response to the question of how she felt after seeing a news item about the victims of an earthquake in Nepal that occurred in April, 2015, nine months before. Her answer reflects what many of the other participants also expressed: an (often unsuccessful) attempt to empathize with the victim, self-awareness of their own lack of care towards those they see suffering onscreen, and their moral and emotional struggle to deal with this lack of empathy.

In the last few decades, the interdisciplinary study of mediated distant suffering has seen significant growth. Earlier research has often focused on moral and theoretical questions about the scope of care of the predominantly Western spectator for non-Western victims (cf. Boltanski, 1999; Cohen, 2001; Moeller, 1999) or on text-based studies about dominant modes of discourse concerning distant suffering (cf. Chouliaraki, 2006; Joye, 2010). However, recently, there has been a growing body of literature concerned with empirical studies about audience reactions to distant suffering (Höijer, 2004; Kyriakidou, 2014; Scott, 2014, 2015; Seu, 2010, 2015; von Engelhardt and Jansz, 2014). Subscribing ourselves to the latter tradition of research, the main focus of this study was to ascertain how domesticated news of distant suffering can actually invite people in a western setting to care. The potential of domestication in the context of suffering has previously been investigated, although predominantly from the production side. For instance, based on a critical discourse analysis, previous work has demonstrated several strategies of domestication that can bring distant suffering closer to the spectator, which can potentially lead to an increased sense of care and compassion (Joye, 2015). Although most research on domestication thus looks at the 
producers'/journalists' side of the story and/or relies on a textual analysis, this article urges to include the audience into the equation. How do domesticating strategies resonate amongst an audience? How do people make sense of dominant discourses from the news? After a brief literature review on the practice of domesticating distant suffering, the central concept of care will be operationalized for a more structured and clear empirical analysis of viewers' reactions to distant suffering. This is followed by an analysis of ten focus groups that were conducted in Belgium in 2016. We believe that Belgium, as exemplar for western democracies in terms of social welfare, state of journalism and richness of media outlets, can help us to gain more understanding about the perspective of a western spectator towards the distant suffering.

\section{Domesticating distant suffering}

The journalistic practice of domestication generally refers to the framing of a foreign news event within the perceived national or local context of the audience (Clausen, 2004). Although integrating such a local or domestic perspective is nothing new - in 1979, Peterson stated that 'the majority of foreign news is domestic news about foreign countries, not international news' (p. 120) — it does appear to thrive in contemporary news reporting (Chang et al., 2012). According to Gurevitch, Levy, and Roeh (1991), domesticating international events makes them comprehensible, appealing, and more relevant to local audiences. Although domestication is also defined as 'the discursive adaptation of news from 'outside' the nation-state so as to make it resonate with a national audience as it is perceived' (Olausson, 2014: 711, emphasis added), we can easily understand why most research has chosen to focus on the production side and on the journalists whose discursive practices are investigated through textual analysis (Alasuutari et al., 2013; Olausson, 2014; Joye, 2015). For instance, Alasuutari et al. (2013) examined the range of constructed interconnections 
between the domestic and the global in news reporting on the Arab Spring and identified four modes of domestication: appealing to emotions, focusing on compatriots involved in the events, reporting on statements and acts by domestic actors, and utilizing the foreign event as a model that can be applied to local politics. Observing the range of constructed interconnections between the domestic and the global in news reporting on climate change, Olausson (2014: 715) has identified three discursive modes of domestication: '(1) introverted domestication, which disconnects the domestic from the global; (2) extroverted domestication, which interconnects the domestic and the global; and (3) counterdomestication, a deterritorialized mode of reporting that lacks any domestic epicenter.'

These discursive modes of domesticating international news were first explicitly linked to mediated distant suffering when we uncovered four dominant strategies of domestication employed by news producers to invite the audience to care (Joye, 2015). First, we found that journalists domesticate distant suffering by selecting emotionally narrated stories or eyewitness accounts of compatriots who were affected by the foreign event (emotional domestication). A second domestication method focuses on aid-driven messages and is thus called aid-driven domestication. The third method, familiarizing the unfamiliar, is done by using certain narratives and styles to create a sense of familiarity and recognition surrounding events that might otherwise be impossible to imagine (i.e., hunger, famine, and earthquakes are difficult to understand or imagine for a Western audience due to the absence of experiential overlap). A fourth strategy is to discursively link the risks and stakes of the foreign event to the home country, a strategy we call 'what are the stakes.' These four presented modes of domestication of distant suffering are theorized as being possibly effective for bringing distant suffering closer to the audience and inviting them to care.

\section{To care or not to care; that is the question}


Within the emerging academic field of distant suffering, concepts such as care, compassion, pity, sympathy, and empathy are regularly (and sometimes interchangeably) mentioned, but less often clearly defined and/or conceptualized. For this article, which draws on audience research in the context of mediated suffering, we argue for a more clear and delineated conceptualization. Future research could build further on the current conceptualization and definitions to guarantee continuity of current and future empirical audience research and research into mediated distant suffering.

Inspired by von Engelhardt (2015) and Huiberts and Joye (2015), we will conceptualize and operationalize the central notions of care and compassion using social psychological and moral psychological concepts. These psychological traditions differentiate between emotional and rational processes that can both lead to a sense of care and compassion. In this study, the two concepts of care and compassion are used interchangeably because both are the result of an interplay of emotional (empathetic) processes and rational (sympathetic) processes, which results in a sense of moral responsibility to help. Compassion is generally defined in the field of moral psychology as " "the feeling that arises in witnessing another's suffering and that motivates a subsequent desire to help"' (Goetz et al., 2010 in von Engelhardt, 2015 p. 698), which bears many similarities with the definition of 'care.'

From the social psychological tradition, we have learned to take into account how people think (cognition), feel (affect), and behave (Ross and Nisbett, 1991; Vaughan and Hogg, 2010). To make sense of the concept of care in a context of mediated distant suffering and audience reactions towards it, we have chosen to extrapolate this sentiment along the lines of the above mentioned 'tripod' of cognition, affect, and behavior (Huiberts and Joye, 2015; Ross and Nisbett, 1991). More specifically, for this study, the concept of care/compassion is subdivided into empathy — which is more related to people's emotional reactions — and sympathy, which is more on the cognitive side of this continuum. However, it is important to 
acknowledge that these sentiments are neither completely emotionally based nor cognitively reasoned; they are rather a result of a complex and often subconscious interplay between these processes (see also Loewenstein and Small, 2007; Haidt, 2001; von Engelhardt, 2015).

\section{Empathy}

Von Engelhardt asserts that experiencing empathy 'involves understanding another's affective state (cognitive component of empathy) or an actual vicarious emotional experience (affective component of empathy)' (Danis, 2006 and Eisenberg, 2000 in von Engelhardt, 2015: 699). Although there are indeed cognitive processes involved in empathetic reactions, in empathy, the focus lies on the affective state of both the sufferer and the spectator. The focus is on the capability of the spectator to crawl into the skin of the sufferer and feel what the sufferer feels, what is generally labeled as inciting experiential overlap. Such affective states are at the center of this article, especially that of the spectator and their attempt to emotionally experience the depicted suffering. Proximity, membership in one's in-group, and a sense of perceived similarity are significant in facilitating empathy towards mediated suffering (Loewenstein and Small, 2007). Domestication of distant suffering, by for instance creating a sense of emotional proximity (for example by including someone from the home country into the narrative, see Joye, 2015), is thus an appropriate strategy to incite an affective state of empathy. We expect that viewers are more likely to identify and consequently empathize with suffering if a news item features someone who is more recognizable to the home audience who explains the kind of suffering foreigners experience.

\section{Sympathy}

In field of moral psychology, sympathy does 'not so much involve experiencing the emotions of another as an effort to understand the difficulties faced by another and to emit 
supportive and caring responses' (Turner and Stets, 2006, in von Engelhardt, 2015: 699). In contrast with the emotionally- based sentiment of empathy, we consider sympathy to be the more rational component of caring. It is less about crawling into the skin of the victim and more about creating an understanding about the difficulties and needs of the victim. It thus leads to a sense of care that requires an action to help. In other words, sympathy involves the kind of reasoning that can, in the end, lead to an idea of one's own moral code of conduct in relation to the victim. Domesticating strategies that aim to enhance a sense of understanding might lead spectators to be more sympathetic towards distant suffering. For example, because it can be difficult for a mainly Western audience to imagine what it is like to be starving, news narratives can be adjusted so that such an unfamiliar situation becomes slightly less unfamiliar and facilitate a reaction of sympathy (Huiberts and Joye, 2015). In addition, such understanding could lead to a sense of moral responsibility to help the victims.

\section{Strategies of denial}

Besides empathetic or sympathetic reactions, we also expect people to react to the mediated distant suffering by denying or neutralizing the suffering or their sense of moral responsibility towards those suffering (Cohen, 2001; Seu, 2010). Seu (2010) describes three repertoires to strategically neutralize the depicted suffering and the audience's lack of moral or emotional involvement, which she has called 'strategies of denial'. The first strategy is to neutralize the message itself. In this strategy, the message is considered to be manipulative or biased, which makes it more acceptable to dismiss the message as a spectator, as an act of resistance against said manipulation. The second strategy is to criticize the media—'shoot the messenger' - so that the message itself is neutralized (Seu, 2010: 446). Lastly, inaction can be justified by stressing the ineffectiveness of help organizations, which Seu aptly names the 'babies and bathwater' strategy (p. 439). 
From a moral psychological point of view, these reactions remind us of Haidt's argument that moral judgements are intuitively made rather than rationally, and they are rationalized after moral judgements are made, by what he calls 'post-hoc constructions' (2001: 814). Haidt asserts that 'moral intuitions (including moral emotions) come first and directly cause moral judgement' (2001: 814). He aptly calls this 'the emotional dog and its rational tail.' We would expect such hindsight rationalization of moral behavior to occur in the way that Seu (2010) has described.

Von Engelhardt (2015) differentiates between empathy, sympathy, and compassion. Seu has described 'strategies of denial,' and Haidt (2001) speaks of rationality and intuition, reasoning and emotion. What all three theorists have in common is that they differentiate between emotional (affective) and reasoned (cognitive/rational) mental processes and the interaction of these processes leading to (moral) (in)action or compassion/care. We follow this tradition and thus differentiate between empathy (the affective process) and sympathy (a more rational process), which both lead to a sense of care/compassion.

\section{$\underline{\text { Methodology }}$}

For this study, we conducted ten focus groups. A total of 51 people from the Flemish, Dutch-speaking part of Belgium were selected based on gender, education, and age (see table 1). The study starts from a critical realistic perspective, which 'embraces naturalistic explanations in the social sciences without ignoring, at the same time, the fact men and women, unlike natural entities, actively reproduce their social world' (Harvey 2002: 163). In addition and more specifically, we follow Stuart Hall's (2001) tradition within audience reception studies as he describes a non-linear process of exchanging messages that includes the interlinked processes of 'encoding' and 'decoding' within all acts of communication. By adopting this non-linear and dynamic description of media in relation to the audience, we 
acknowledge the (inter)active and recursive relationship that people in the audience have with the media and media producers. In addition, we take into account the diverse ways in which any message may be related to, or can be interpreted by its receiver.

Table 1 about here

During the focus groups, people discussed their news consumption and routines and their experiences with news from distant places. They were shown a news item about the earthquake in Nepal, which was aired on the same day that the earthquake occurred, 25 April 2015 , roughly nine months before the focus groups were held. The news item shows many injured and confused citizens of Kathmandu, collapsing buildings, and total chaos. It also reports the experience of a Belgian citizen who runs an orphanage in Kathmandu, who is interviewed over the phone and testifies to how scared he was when it all happened and how they were all 'really, really scared.'2 After this, an Indian citizen is interviewed, and he describes feeling the earthquake, even though it occurred far away. This video was chosen because of its clear strategy of domesticating the distant suffering by including the testimony of a Belgian citizen. It also reminds us of Chouliaraki's (2006: 119) description of 'emergency news,' the kind of news that can lead to a sense of cosmopolitanism based on a sense of solidarity towards the distant suffering. The articulated discourse of emergency news, as well as the clear strategy of domestication, are regarded as clear journalistic choices to invite the audience to care about the foreign event.

After viewing the news item, people were explicitly asked to discuss how they felt towards the suffering, both in terms of emotional reactions and in terms of any (in)action they wanted to carry out. We asked whether people would want to do anything (monetary donation, giving clothes, volunteering, et cetera) and why or why not. Their considerations to 
(not) respond to the distant suffering can indicate how people explain their own moral and emotional struggle in the face of distant suffering that inherently calls for moral (re)action. We also payed attention to how the respondents reacted towards the Belgian eyewitness and whether his Belgian narrative made a difference.

\section{$\underline{\text { Analysis }}$}

During the focus groups sessions, we found that many respondents experienced difficulties empathizing with the Nepali victims. While discussing their efforts to empathize with the victims, it became clear that strategies of domestication are a useful tool for bringing suffering closer, not only for the media but also for the audience. However, more often than not, attempts to empathize or to sympathize with suffering go hand-in-hand with strategies to deny the suffering or to rationalize their own moral inaction or indifference towards it. Let us take a closer look at these reactions of empathy, denial, and sympathy in the context of domesticated suffering.

Empathy: 'It's about how he feels it all.'

As may already have been noticed at the beginning of this article, the very first thing Meredith (see introductory quote) talks about is her difficulty empathizing with the distant other after she saw the images of the earthquake in Nepal. Meredith's failed attempt to empathize and her confession that she actually forgets about the suffering 'the next day' was described by many participants and often for the same reason: the suffering being too far (both culturally or geographically) and the unlikelihood of the events happening 'here' in the group members' own vicinity.

As mentioned earlier, the emotional domestication of distant suffering by journalistswhich we can define as first-level domestication on the production side of the news process- 
can facilitate a sense of emotional proximity (Joye, 2015). We noticed that many of our respondents deployed similar strategies of domestication in an attempt to empathize with the distant suffering. They would for example realize after watching the news item that the Flemish man who runs the orphanage helped them to be more moved or concerned by the events. We will refer to these practices or strategies on behalf of the audience as second-level domestication. For example, John (28) admitted:

I do notice from myself that I pay more attention when he (the Flemish man from the orphanage) begins to tell his story [...] because it's his story, it's not some kind of report, it's about how he feels it all (focus group 8, mixed group, high education level).

Besides such explicit demands for or appreciation of domestication, a subtler, and perhaps more surprising, domestication strategy was reflected in the manner that most participants remembered the events of Nepal. During the time of the Nepal earthquake, the national Belgium first aid and support team, B-FAST, was sent to the disaster site, but after not being able to land in Kathmandu, it returned to Belgium without ever having helped in Nepal. ${ }^{1}$ In eight out of ten focus groups, the B-FAST incident was the very first thing group members discussed after being asked what they remembered about the earthquake in Nepal. Whereas the scholarly literature on domestication mainly situates the relevance of domesticating strategies in the field of news processing or witnessing, our study suggests the value of these strategies in remembering and recalling events. This domesticating strategy is not like any of the four kinds of domestication found on the production side. Rather, it is a

\footnotetext{
${ }^{1}$ See for example: http://www.flanderstoday.eu/current-affairs/week-brief-4-may
} 
second-level domestication that could be seen as the clear result of domesticating strategies by news producers. Indeed, the group members memories about the B-FAST incident clearly resonate with the dominant modes of discourse that were found in the media at the time of the incident.

One way of coping with the realization of a lack of empathy is to strategically emphasize the impossibility of being emotionally moved or involved with everything that the participants would see on the news, so that they felt compelled to prioritize news based on what events have a greater chance of happening in their home country. Respondents explained that events that happen closer to home, where the stakes are higher, provoke a far more emotional response than suffering that occurs far away. These thoughts are very similar to the discursive modes of domestication that journalists use in reporting on foreign events ('what are the stakes?') and thus are a second manifestation of what we have called a second-level domestication by the audience. Most reflective of this was our respondents' comparison of the victims in Nepal with the victims in Paris after the terrorist attacks in November, 2015, three months before these focus groups were carried out. They could not easily identify with citizens in Nepal, nor imagine what it would be like to experience the devastation of an earthquake. On the other hand, the Paris attacks happened only a three-hour drive away from the participants and were far more likely to also occur in Belgium (in fact, similar attacks did unfortunately occur on the morning of 22 March 2016, when there was an attack in Brussels). For example, Eva (51) explained:

What happened in Paris has a greater impact on me because, well, our daughter had to go to Brussels that day and I was scared [...] It (the news about Paris) moves you more. And don't get me wrong, it's terrible for those people there (in Nepal), but I think, I hope at least, I will never be 
confronted with an earthquake (focus group 2, female group, high education level).

At the same time, they were critical of themselves and aware of their own lack of caring about distant suffering, as Jean (59) said: 'I was shocked by myself, by myself paying more attention to the Flemish guy because he was Flemish, and I was listening to him because he was Flemish (focus group 9, mixed group, high education level).

There were more participants going through the kind of moral struggle that Jean went through. Many were also self-aware and self-critical of the influence that the media has on the way they perceive, react to, and feel about events on the news. Carry (22) stated:

There was news about Paris every five minutes, and it was always updated. But there were also attacks in Jakarta, but that only lasts two minutes, and then it stops. And so, it stops for me too, because I'm not looking further into that (focus group 6, mixed group, high education level).

People were far more capable of empathizing with mediated suffering when they experienced a more personal connection to the suffering. This personal connection was often based on a sense of cultural similarity, shared experience, or geographical proximity. The proximity of an event and cultural similarity enabled people to better emotionally imagine what the distant sufferer is going through, leading to a sense of shared or overlapping experience. This was most obvious when the participants discussed their reactions to the events in Paris as compared to the events in Nepal. In general, distance makes it difficult to empathize with something or someone. Both cultural and geographical distance makes the mediated event more abstract, less tangible, and more difficult to identify with or to imagine 
what it must have been like. None of the respondents had experienced an earthquake, and they found it very hard to imagine what it would be like. In response to this ascertainment, viewers used (second-level) emotional domestication strategies to be more emotionally moved by the mediated distant suffering, and these strategies are similar to the first-level strategies employed by media producers. Participants did this by emphasizing the link between the tragedy and their home country (by noticing and listening to the Belgian citizen who was in Nepal) or by considering the risks of a similar event happening in their home country.

Sympathy: 'Mind you, that doesn't mean that you don't empathize.'

Even if the more emotionally based feeling of empathy is difficult to invoke through media reports, it could be argued that people can still be caring and compassionate, albeit in a more reasoned way, by sympathizing with the victims. As mentioned before, sympathy (cf. von Engelhardt, 2015) is based on a sense of understanding, an acknowledgement of the difficulties of those suffering, and a moral desire to help those who suffer. Most participants were reluctant to help, donate, or perform any other action to relieve the suffering. They used strategies of denial, as described by Seu (2010) to explain these inactions, (more about this later in this article). However, at the same time, most were self-reflective about their inaction, and some tried to compensate for their lack of action by stressing their concern about the suffering, even though they could not imagine what it was like. For example, Janne (21) stated:

Ah, well, I think it is really hard to empathize because it's so far away. But mind you, that doesn't mean that you don't empathize. I don't know... But, for example those falling towers, that's probably really important for the 
local people over there. It would be similar to having church towers falling right here (focus group 5, female group, low education level).

Janne tries to understand the suffering of those who live far away by comparing the falling towers in Nepal with falling church towers in her home country, which reflects the domestication strategy of familiarizing the unfamiliar that is also seen on the production side (Joye, 2015).

Focus group members also tried to sympathize by relating events in distant places to those in their own nation, which is similar to the strategy of first-level domestication, i.e., 'what's at stake for us?' (Joye, 2015: 688). Yet, events such as the earthquake in Nepal have no relation to or consequence for the group members' home country of Belgium. In this case, such a domestication strategy misses the aim of encouraging sympathy and leads to events becoming more distant rather than proximate, because there are no stakes for the home country, and there are no similarities to the situation in the home country. This becomes clear in the following quote by Juliette (25):

It (the earthquake) is the kind of thing that we never experienced. [...] It's terrible, terrible. I think about what that would be like here, if that happened here. And I think how lucky I am for living in a country where everything is flat and nothing moves around (focus group 7, mixed group, low education level).

To sympathize with the distant sufferer, the audience thus applied several strategies of second-level domestication, which are again very similar to those used on the production side of the news. Besides looking for an emotional connection, participants tried to familiarize the unfamiliar and consider the consequences of the far-away events to their home country by 
considering 'what are the stakes for us.' Of these latter two domestication strategies employed by the audience, only the first (familiarizing the unfamiliar) proved to be effective in provoking sympathy with distant suffering. The latter generally only made distant events even more distant and abstract.

Denial: 'It's terrible, BUT...'

Shepherd (2003: 497) argued that it is impossible to acknowledge all moral appeals that are made in daily life — either mediated or in proximate reality_-because if people heard all these moral calls, the phone would be 'ringing off the hook.' Not all moral appeals can be recognized, which could lead to, what Cohen has called 'selective oblivion,' the act of not paying attention to all the suffering that is mediated in order to cope with an otherwise 'overload of information' (2001: 187). The question of which moral appeals should, or can, be answered and which are allowed to be ignored is a daily moral struggle, which was also vividly discussed amongst the participants during the focus groups. As already briefly mentioned, people used tactics similar to Seu's earlier described 'strategies of denial' (2010) to cope with their own lack of empathetic and sympathetic moral reactions towards suffering.

For one, some group members expressed a degree of cynicism towards the message as being 'one in a dozen,' thereby neutralizing the message. They put forward that the message is too typical and the format so recognizable that they would have trouble being emotionally moved or even interested because they had seen these kinds of messages too often and had become desensitized:

Well, it's awful, but I realize that such a video doesn't shock me at all. It's something I've seen a thousand times already, you know? It's terrible to 
say, but you'd really have to see it in real life to be really impressed

(Evelien, 23, focus group 5, female group, low education level).

And Ashu (20) said: 'To put it bluntly, but “boring”. I've already seen this. They might as well have shown a video clip of an earthquake that maybe happened in Nepal like two or three years ago' (focus group 8, mixed group, high education level).

Second, they would be inclined to 'shoot the messenger' which is in interesting contradiction to other statements the respondents made about news reports having more emotional impact if they hit closer to home or are presented on a more personal (and thus domesticated) level (see above). They were very critical about the news item reporting that no Belgians were affected or killed during the event (thus, shooting the messenger). More generally, respondents were critical about the overall news media's persistent focus on the Belgian relief team B-FAST not being able to start its operations in Nepal. Because this narrative focus on the home country and compatriots abroad is one of the most common ways of domesticating a foreign event, our results indicate a rather media savvy audience. They know why the journalists use practices of domestication and what journalists want to achieve with it, and they can identify these strategies of domestication. This media knowledge is present to such an extent that some respondents expressed a degree of cynicism. They found the media tactics too obvious, cheap, unnecessary, and even disrespectful towards the other (local) victims:

It might have been more interesting to have a local person interviewed because personally, it can bother me to see that when something bad has happened, they mention something like 'there are 200 people killed, but luckily there were no Belgians involved'. [... I can get a wry sense from that (Maurits, 20, focus group 1, male group, high education level). 
Seu's third strategy of denial ('throwing the baby out with the bathwater') was also often used by participants. Many asserted their own lack of agency towards those suffering and expressed a sense of powerlessness that they felt was very frustrating. For example, Karim (20) stated that 'Poverty will always exist' (focus group 7, mixed group, low education level). One way of coping with that was to express the ineffectiveness of donating to humanitarian aid organizations because they are seen as untrustworthy, bureaucratic, and possibly even corrupt (a kind of reasoning that is indeed similar to throwing out the "baby with the bathwater' [Seu, 2010: 449]). Sylvia's (43) commentary about the Belgian national help organization B-FAST is reflective of this: 'I'm rather cynical about that. I tend to think, what kind of percentage will eventually end up there? If all the money had gone to B-FAST, we wouldn't have done a thing. I'm really skeptical about that' (focus group 2, female group, high education level).

Looking closer at the comments of both Maurits (20) (above) and Meredith (23) (introductory quote), we can see that their expressed lack of care towards suffering is related to expressions of being morally uncomfortable about it. Most respondents were able to selfreflect and consequently were self-aware and critical about their disengaged (and sometimes even contradicting) attitude towards victims in far-away places. As Melanie (31) stated:

All these troubled images they announce, the sensitive images, ... I find myself not really dwelling on it. There's all those dead people, lying there, slaughtered or something, and I am making my dinner. I mean, my children are there too, then. I can think then, oh that's really awful (to not dwell on it) (focus group 8, mixed group, high education level). 
Aid-driven or emergency driven messages - a way of domesticating the distant suffering by creating a sense of moral responsibility amongst viewers — did not seem to increase the participants' sense of moral responsibility. Indeed, moral calls were more often dismissed by strategies already identified earlier by Seu in 2010 .

\section{Conclusion}

Drawing on a focus group study, we demonstrated the relevance and value of incorporating the audience into research on the practice of domestication in international news coverage. Our findings suggest a two-flow model of domestication: first-level domestication that is situated on the production side of the news process and second-level domestication on the reception side. Although the practice of domestication is praised for bringing distant events closer and thus rendering them more relevant and appealing, our study demonstrates that not all strategies of domestication are equally effective. Emotional domestication was more effective than strategies based on moral appeals (i.e., aid-driven messages) or rational considerations of risk (i.e., 'what are the stakes?'). These latter strategies were used more often to explain focus group members' indifference and lack of care thus dismissing moral appeals. Still, sympathy — another more rational reaction towards the victims, in which the aim is to gain a better understanding of the experience of those suffering — was elicited by the domestication strategy of 'familiarizing the unfamiliar.'

We propose that a sense of experiential overlap, be it imagined or real, more easily facilitates a sense of care. Von Engelhardt (2015: 700) has suggested that a lack of experiential overlap might be 'an obstacle to empathetic responses towards distant victims that is greater than those created by geographical distance and perceived cultural or ethnic dissimilarity.' According to the results of this study, von Engelhardt's emphasis on the importance of experiential overlap is confirmed. Audiences domesticate the distant event and 
make it relevant and real to themselves by imagining how they would react to the event based on pre-existing perceptions and their own experiences. Indeed, the second-level domestication strategies that were used and proved to be most effective for the audience were those that aimed to imagine or create a shared experience, either emotionally by narratively focusing on someone from the home country or by familiarizing the unfamiliar (e.g., comparing a collapsed building in Nepal with a collapsed building in Belgium).

The complex and sometimes contradictory (lack of) feelings of empathy, sympathetic expression, and strategies of denial show the moral struggle that participants go through, and there is no singular, easy or 'right' answer to the way that people ought to, or in fact do, react towards mediated distant suffering. We argue that, in line with Haidt's (2001) explanation, moral judgements are made intuitively and emotionally rather than rationally. Explanations for (lack of) moral engagement that are put forward are stated after they made their moral judgement, rather than before. The explanations of our respondents for either sympathizing or for their indifference or lack of moral involvement remind us of the kind of 'post-hoc' reasoning that Haidt described (2001: 815). The need for an experiential overlap, the emotional strategies of second-level domestication employed by the audience, and the seemingly intuitive moral explanation for a (lack of) moral engagement and sympathy all point towards the idea that the audience's emotional sense of care (or empathy) is of greater importance to people's sense of care towards the distant suffering than the more rational sense of sympathy. Addressing people's intuitive sense of morality is likely to be more effective in provoking compassion than a more direct moral appeal, which is more easily dismissed.

To end with a critical note, it can be questioned whether emotional kinds of domestication are effective ways to invite an audience to be more engaged with distant suffering. Such strategies may in fact be just another example of audience members being the 'ironic spectators' about whom Chouliaraki wrote in 2013. These spectators engage with the 
suffering from a self-centered position, still in the role of the Western viewer, as opposed to participating in a cosmopolitan sense of solidarity, moral responsibility, and care. However, this article has not focused on moral questions of how audiences should react. Rather, it is a study of the 'lay' morality that people use in their daily lives and of how viewers deal with being confronted with the moral question of how far their scope of care should reach. Previous academic work — theoretical and empirical — has been conducted on the scope of care and compassion towards distant suffering, often drawing on text-based or audience-based research. Coming back full circle, future research could dive into morally loaded questions again, now even more equipped because of new empirical knowledge that informs the evercontinuing moral debate. In terms of methodology and research designs, we see additional value in investigating the audience at a greater scale by means of surveys while other types of media - such as documentaries, film, reality television or online footage - might elicit different responses of an audience. Textual empirical research about mediated suffering in context of online media (Pantti, 2015) and reality television (Cover, 2013; Nikunen, 2015; Price, 2014) already offer new opportunities for audience researchers to further explore.

\footnotetext{
${ }^{1}$ All quotes presented in this article are translated from Dutch, the language that was used during the focus groups. In addition, to protect the privacy of the participants, all names have been changed.

${ }^{2}$ For the footage, see http://nieuws.vtm.be/buitenland/138565-honderden-doden-bijaardbeving-nepal
} 


\section{$\underline{\text { Bibliography }}$}

Alasuutari, P, Qadir, A and Creutz, K. (2013) 'The Domestication of Foreign News: News Stories Related to the 2011 Egyptian Revolution in British, Finnish and Pakistani Newspapers', Media, Culture \& Society 35(6): 692-707.

Boltanski, L. (1999) Distant Suffering: Morality, Media and Politics. Cambridge: Cambridge University Press.

Chang TK, Southwell, B, Lee, HM, Hong, Y (2012) ‘A Changing World, Unchanging Perspectives: American Newspaper Editors and Enduring Values in Foreign News Reporting', International Communication Gazette 74(4): 367-384.

Chouliaraki, L. (2006) The Spectatorship of Suffering, London: Sage Publications Limited.

Chouliaraki, L. (2013) The Ironic Spectator, Cambridge: Polity Press.

Clausen, L. (2004) 'Localizing the Global: 'Domestication' Processes in International News Production', Media, Culture \& Society 26(1): 25-44.

Cohen, S. (2001) States of Denial: Knowing About Atrocities and Suffering. Oxford: Blackwell Publishers Ltd.

Cover, R. (2013) 'Undoing Attitudes: Subjectivity and Ethical Change in the Go Back To Where You Came From Documentary', Continuum 27(3): 408-420.

Joye, S. (2010) 'News Discourses on Distant Suffering: A Critical Discourse Analysis of the 2003 Sars Outbreak', Discourse \& Society 21(5): 586-601.

Joye, S. (2015) 'Domesticating Distant Suffering: How Can News Media Discursively Invite the Audience to Care?', International Communication Gazette 77(7): 682-694.

Gurevitch, M, Levy, MR and Roeh, I. (1991) 'The Global Newsroom: Convergences and Diversities in the Globalization of Television News', pp. 195-216 in P. Dahlgren and C. Sparks (eds) Communication and citizenship: Journalism and the public sphere in the new media age. London: Routledge. 
Haidt, J. (2001) 'The Emotional Dog and Its Rational Tail: A Social Intuitionist Approach to Moral Judgment', Psychological review 108(4): 814-834.

Hall, S. (2001) 'Encoding/decoding’, pp 163-173 in MG. Durham and DM. Kellner (eds) Media and Cultural Studies: Keyworks. Malden: Blackwell Publishing.

Harvey, DL. (2002) 'Agency and Community: A Critical Realist Paradigm', Journal for the Theory of Social Behaviour 32(2): 163-194.

Höijer, B. (2004) 'The Discourse of Global Compassion: The Audience and Media Reporting of Human Suffering', Media, Culture \& Society 26(4): 513-531.

Hope, A. (2015) The week in brief: 4 May, Flanders Today. Belgium.

Huiberts, E. and Joye, S. (2015) “"Bring in the Audience!” Exploring an Interdisciplinary Approach to Investigating Audience Reactions to Mediated Distant Suffering', Networking Knowledge 8(1): 1-15.

Kyriakidou, M. (2014) 'Distant Suffering in Audience Memory: The Moral Hierarchy of Remembering’, International Journal of Communication 8: 1474-1494.

Loewenstein, G. and Small, DA. (2007) 'The Scarecrow and the Tin Man: The Vicissitudes of Human Sympathy and Caring', Review of General Psychology 11(2): 112-126.

Moeller, SD. (1999) Compassion Fatigue: How the Media Sell Disease, Famine, War And Death. New York: Routledge.

Nikunen, K. (2015) 'Media, Passion and Humanitarian Reality Television', European Journal of Cultural Studies 19(3): 265-282.

Olausson, U. (2014) 'The Diversified Nature of "Domesticated” News Discourse: The Case of Climate Change in National News Media', Journalism Studies 15(6): 711-725.

Pantti, M. (2015) 'Grassroots Humanitarianism on Youtube: Ordinary Fundraisers, Unlikely Donors, and Global Solidarity', International Communication Gazette 77(7): 622-636. 
Peterson, S. (1979) Foreign News Gatekeepers and Criteria of Newsworthiness', Journalism and Mass Communication Quarterly 56(1): 116-125.

Price, E. (2014) 'Empathy or entitlement? Humanizing and Othering discourses in Go Back To Where You Came From', The Journal of Popular Television 2(1): 97-110.

Ross, L and Nisbett, RE. (1991) The person and the Situation: Perspectives of Social Psychology. New York: Mcgraw-Hill Book Company.

Scott, M. (2014) 'The Mediation of Distant Suffering: An Empirical Contribution Beyond Television News Texts', Media, Culture \& Society 36(1): 3-19.

Scott, M. (2015) 'Distant Suffering Online: The Unfortunate Irony of Cyber-Utopian Narratives', International Communication Gazette 77(7): 637-653.

Seu, IB. (2010) “'Doing Denial': Audience Reaction to Human Rights Appeals', Discourse \& Society 21(4): 438-457.

Seu, IB. (2015) 'Appealing Children: Uk Audiences' Responses to the Use of Children in Humanitarian Communications', International Communication Gazette 77(7): 654667.

Shepherd, L. (2003) 'Face to Face: A Call for Radical Responsibility in Place of Compassion', St. John's Law Review 77(3): 445-514.

Vaughan, G and Hogg, MA. (2010) Introduction to Social Psychology. Essex: Pearson Education Australia.

Vlaamse Televisie Maatschappij VTM nieuws (2015) Honderden doden bij aardbeving Nepal (Hundreds dead at earthquake Nepal). Belgium: VTM Nieuws, 1:59. Video item available at http://nieuws.vtm.be/buitenland/138565-honderden-doden-bij-aardbeving$\underline{\text { nepal }}$ 
von Engelhardt, J. (2015) 'Studying Western audiences vis-à-vis Mediated Distant Suffering. A Call to Venture Beyond Media Studies', International Communication Gazette 77(7): 695-707.

von Engelhardt, J and Jansz, J. (2014) 'Challenging Humanitarian Communication: An Empirical Exploration of Kony 2012', International Communication Gazette 76(6): 464-484. 